\begin{tabular}{l} 
This is an Accepted Manuscript of an article published by \\
Taylor \& Francis in Journal of Youth Studies on 31 August \\
2018, \\
available \\
\hline https://doi.org/10.1080/13676261.2018.1510176
\end{tabular}

Without prejudice to other rights expressly allowed by the copyright holders, this publication can be read, saved and printed for research, teaching and private study. Any other noncommercial and commercial uses are forbidden without the written permission of the copyright holders. 


\title{
Contextual moderators of the link between national and European identity among European youth
}

\author{
Philipp Jugert $^{\text {a }}$, Jan Šerek ${ }^{\mathrm{b}}$, \& Janine Stollberg ${ }^{\mathrm{c}}$
}

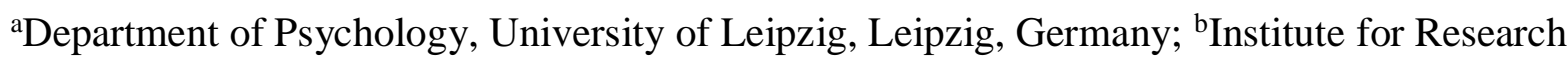
on Children, Youth and Family, Faculty of Social Studies, Masaryk University, Brno, Czech Republic; ' Department of Psychology, University of Salzburg, Salzburg, Austria.

Abstract

Identification with Europe can constitute an important part of psychological citizenship for European citizens. From a self-categorization perspective, higher-order (e.g., with Europe) and lower order subgroup identities (e.g., with the nation) may interfere with each other if they are seen as incompatible. We were interested in contextual moderators at school and country level of youth' national identity on identification with Europe. We used multi-level regression analyses based on data from the International Civic and Citizenship Education Study, collected from 14-year old students ( $n=$ 71,282 ) from 22 European countries. Results showed strong positive effects of national identity at the individual, and classroom-level on European identity. However, main effects of national identity at the individual level were qualified by a number of interactions with contextual-level moderators. The relationship between national and European identity was weaker for adolescents attending classrooms or living in countries with lower average levels of trust in EU institutions. Living in countries with higher gender and income inequalities, less friendly immigration policies, and a communist past lessened the association between national and European identity. Results point to the powerful effects of context in shaping the relationship between national and European identity.

Keywords: European identity; national identity; adolescents; self-categorization theory; social inequality 


\section{Introduction}

European political elites have promoted the idea of European citizenship, not least because of the rise of Eurosceptic politics and the rejection of several European treaties in referendums. Habermas (2011) has stressed the idea that for European citizenship to become meaningful for its citizens it has to be based on a sense of shared identity and common belonging (i.e., a European identity). This common identity is crucial because only when citizens identify with this community will they accept decisions that are made in Brussels (Habermas 2011). A strong European identity may also help to overcome divisions between and stereotypes towards different countries within Europe. Identification with a community surpassing the nation-state is a central characteristic of cosmopolitan dispositions, which have been linked to greater trust and tolerance of immigrants, and ethnic minorities (Keating 2016; Norris and Inglehart 2009). . However, the rise and enlargement of the EU has also coincided with the rise of nativist and right-wing political movements that are aimed against Europeanization and that see their nation's interest in direct opposition to European integration (Hooghe and Marks 2004). This raises the question of how European identity can be strengthened vis-à-vis existing national identities (Hadler, Tsutsui, and Chin 2012). While a number of studies have examined determinants of a European identity, most of them have focused on adults (Agirdag, Huyst, and van Houtte 2012). However, adolescence is a decisive period for developing group identities as context-related patterns of identity development become more pronounced in this life period (Barrett 2007). Therefore, in this paper we were interested in the relationship between national and European identity among adolescents and how this relationship may differ depending on the social context.

Those few studies that have examined determinants of European identity among adolescents have mostly concentrated on individual differences and sociodemographic factors (e.g., Keating 2016; Verhaegen, Hooghe, and Meeusen 2013). But both social identity theory 
(SIT; Tajfel and Turner 1979) and self-categorization theory (SCT; Turner et al. 1987) suggest that social identities and their inter-relationships are strongly context-dependent (Rutland and Cinnirella 2000). The social identity approach (encompassing both SIT and SCT) attempts to explain the relationship between individuals and groups. According to SIT, individuals have a desire for a positive self-concept and are therefore motivated to favor their own group in comparison to other relevant groups to maintain positive distinctiveness of their ingroup (Hornsey 2008). SCT describes that individuals can be members of many different social groups and thus have multiple social identities. A central tenet of SCT is that the process of identity formation and the relationships between social identities is dynamic, fluid, and context dependent. According to SCT, social groups are cognitively represented in terms of prototypes. But the group prototype is not an objective reality but a subjective perception of what the defining characteristics of the group are that varies across contexts (Hornsey 2008).

Thus, from a SCT perspective higher-order (e.g., with Europe) and lower order subgroup identities (e.g., with the nation) may interfere with each other if the prototype of the national ingroup suggests that these identities are incompatible (e.g., in countries with a negative political discourse about the EU). But different levels of identity can also have a positive reinforcing relationship, exemplified in the construct of nested identities (Medrano and Gutiérrez 2001), especially when a subgroup is embedded in a larger umbrella group. This suggests that national and European identity will be positively associated as long as European identity is seen as compatible with national identity (Bruter 2005).

Only a handful of studies have examined the relationship between national and European identity among adolescents (Fuss 2006; Keating 2016; Boehnke and Fuss 2008). These studies suggest that national identity is in general moderately positively associated with European identity. However, none of these studies examined whether the relationship between national and European identity varied as a function of the social context, which may 
suggest different levels of compatibility between both identities. Hence, in this study we wanted to examine whether contextual factors at the level of schools or countries would moderate the relationship between national and European identity.

\section{Predictors of European identity}

We assumed that national identity would be positively associated with European identity even when controlling for a range of factors known to be associated with European identity. According to ecological systems theory (Bronfenbrenner 1979), social context affects individual development through multiple systems, both at the micro-level (e.g., families and schools) and the macro-level (e.g., countries). Thus, at least three types of factors influencing adolescents' national and European identity can be distinguished (cf. Šerek and Jugert 2017): (1) individual psychological factors influencing European identity, (2) social factors formed by characteristics of adolescents' families and schools, and (3) macro factors formed by country-level characteristics (cf. Barrett 2015).

Previous research suggests that socio-demographic variables are associated with European identity, such that girls, and adolescents with immigrant backgrounds are less likely to identify with Europe (Agirdag, Huyst, and van Houtte 2012; Keating 2016; Verhaegen, Hooghe, and Meeusen 2013). One qualitative study suggests that youth with immigrant backgrounds may be less likely to identify with Europe because they equate European with national identity (Faas 2007b). The evidence is less clear for socio-economic status (SES), with some studies finding that SES is positively associated with European identity (Hooghe and Verhaegen 2017; Agirdag, Phalet, and van Houtte 2016) while others found no significant association (Keating 2016; Verhaegen, Hooghe, and Meeusen 2013). Previous research also suggests a range of individual psychological factors that should be positively associated with European identity. Among these are political interest (Verhaegen, Hooghe, and Meeusen 2013), perceived opportunities for learning about Europe at school (Verhaegen, Hooghe, and 
Meeusen 2013; Keating 2016), political trust in EU institutions (Hooghe and Verhaegen 2017), as well as contact with other European cultures or people from other European countries, discussions with parents and peers about various European topics, and foreign language competence (Keating 2016).

At the school level, one study has shown that the SES-composition of schools affects European identity, such that it is lower in schools with lower average SES (Agirdag, Huyst, and van Houtte 2012). The same study also showed a trend that school-level ethnic diversity was weakly negatively associated with European identity. This may suggest that a higher percentage of students with immigrant backgrounds will be negatively related to European identity. In addition to the above-mentioned perceptions about opportunities for learning about Europe, there might also be objective structural differences between schools in the extent to which they provide these learning opportunities. Qualitative work shows that schools that employ policies with an explicit European agenda are able to engender a stronger European identity within their pupils than schools without such a focus (Savvides and Faas 2016; Faas 2007a). We therefore included school-average perceptions of opportunities for learning about Europe in the model. The same reasoning applies to trust in EU institutions which may also differ between schools.

We also considered country-level characteristics at the macro-level. We assumed that European identity is eroded by worse living conditions in the country (Verhaegen, Hooghe, and Quintelier 2014), and greater social inequalities (Wilkinson and Pickett 2017). Economic utilitarian theories assume that individuals base their identification with the EU on rational cost-benefit calculations (Verhaegen, Hooghe, and Quintelier 2014) . Accordingly, one could expect that people in those countries that are economically worse off and thus receive a relatively large proportion of EU funding should be most positively inclined towards Europe. However, previous research suggests that people from those countries that receive more structural funds from the EU (Brinegar, Jolly, and Kitschelt 2004) and from countries with 
less favorable economic conditions support European integration less (Eichenberg and Dalton 1993). Anderson (1998) suggests that this may be because citizens have limited knowledge about the EU and thus use their attitudes toward domestic institutions as proxies for their relationship to the EU. Thus, citizens from economically lower performing countries are likely to be less satisfied with the performance of their domestic political institutions and this may transfer into lower identification with a supranational entity, such as Europe. Wilkinson and Pickett (2017) argue that social inequality leads to health and social problems in part by lowering social cohesion, generalized trust, and civic participation. Social inequality also lowers people's willingness to contribute to the welfare of other people (Paskov and Dewilde 2012), which is arguably one important pillar of the EU enterprise.

Inequalities can exist in relation to income and gender but also in relation to how countries deal with immigrants compared to natives. Another country-level factor in the European context is a communist past of the country. All former communist countries entered the EU much more recently (2004-2007) than those countries without a communist past and there is evidence that late accession is significantly positively associated with European identity (Verhaegen, Hooghe, and Quintelier 2014). Previous studies also established that Euroscepticism at the country-level is negatively associated with European identity (Verhaegen and Hooghe 2015; Verhaegen, Hooghe, and Meeusen 2013; Keating 2016). Because Euroscepticism is conceptually similar to trust in EU institutions and we wanted to be consistent in our measures across levels, we used country-average levels of trust in EU institutions as a proxy for country-level Euroscepticism.

\section{Moderators of the association between national and European identity}

The main concern of this paper were contextual factors at the school and country-level that moderate the relationship between national and European identity. Following SCT, we assumed that factors that make national and European identity incompatible should moderate 
their relationship.

One such factor may be Eurosceptic attitudes represented by trust in EU institutions. According to SCT, when acting in terms of group identity, we tend to perceive ourselves and act based on the characteristics associated with the groups to which we belong. In other words, in group contexts we tend to stereotype ourselves based on what we perceive as norms of our in-groups. Thus, if we believe that distrust in the EU is an important part of our group identity in some contexts (e.g., we believe that "we, in our school or country, do not trust the EU"), an activation of these group identities will be associated with our decreased tendency to trust the EU, or more generally, our decreased tendency to identify with Europe. Hence, if trust in the EU is low at the school or country level, it is suggestive of a group norm of distrust in the EU and may put national and European identities in conflict. Consequently, we assumed that national identity should be less strongly related to European identity in schools or countries with lower average levels of trust in EU institutions.

Another moderator may be collectively shared economic hardship (lower school-level SES or lower country-level GDP) and inequalities (higher country-level income or gender inequality). Following SIT, unfavourable economic or social circumstances of one's group, compared to other groups, poses a threat to collective self-esteem. One of the strategies to cope with this aversive situation is to re-establish perceived positive distinctiveness between one's and other groups by emphasizing inter-group differences in a way that favours one's group (Tajfel and Turner 1979). For instance, people from socioeconomically disadvantaged countries and other social groups might tend to emphasize cross-country cultural differences in order to boost their group-based self-esteem. The increased inter-country differentiation, in turn, might make European identity seem less compatible with national identity. This would suggest that under conditions of economic hardship or inequality the relationship between national and European identity is less strong. 
Yet another moderator may be linked to the specific content of national identity, which is co-determined by a country's communist past. Scholars in political science (e.g., Smith 1992) have proposed that there are different notions of national identity in Western and Eastern (post-communist) Europe. Specifically, national identifications in most Western countries tend to be more civically oriented, while identifications in Eastern countries are more based on ethnic descent and cultural ties. Since the EU is a civic entity that has no clear ethnic or cultural basis this would suggest that the relationship between national and European identity should be stronger in countries without a communist past.

A country's immigration friendliness may also moderate the association between national and European identity. The EU actively promotes the rights of immigrants and ethnic minorities and pressures its member states to adapt their policies accordingly. These practices contribute to the expectation that European identity is characterized by its inclusiveness and cosmopolitanism (Keating 2016). Nevertheless, EU countries differ in the way they deal with immigrants, and, based on this, different levels of inclusiveness might be related to national identities across countries. Therefore it is likely that people from countries with harsher immigration policies will perceive their national identity as less compatible with European identity, while the compatibility will be higher among countries with higher levels of immigration friendly policies.

\section{The present study}

Overall, this study examined whether the association between adolescents' national and European identity was moderated by the context of their school (average trust in EU and economic hardship) and country (average trust in EU, economic hardship, level of inequalities, post-communist past, and immigration policy). A positive relationship between national and European identity would suggest compatibility between both identities whereas a negative relationship would suggest incompatibility. A non-significant relationship would 
indicate independence of both identities. Additional moderators (e.g., percentage of students with immigrant background in the classroom) were examined in an exploratory fashion. To be able to clearly distinguish between the predictors of national and European identity, and the moderators of their mutual association, we included both European and national identity as outcome variables before testing the moderation effects. In addition, we controlled for national identity at the individual, school, and country-level when predicting European level identity.

\section{Method}

\section{Participants and procedure}

We reanalyzed cross-national survey data from the 2009 International Civic and Citizenship Education Study (ICCS) and its European Regional Module (ERM). The ICCS questionnaire includes various measures of civic competence and citizenship education. The ERM contains questions specific to Europe and the EU, such as students' attitudes towards and their identification with Europe and their knowledge about the EU. Although the ERM was administered in 24 European countries, we used a subset of 22 countries that were members of the European Union at the time of data collection. The sampling design ensured that samples were representative of the participating countries and sampled one classroom per

school (Schulz, Ainley, and Fraillon 2011). The data have a hierarchical structure with 71,282 eighth-graders who were on average 14 years old (level 1) and who were nested in 3,632 classrooms (level 2; $M$ classroom size $=19.62)$ that were nested in 22 countries (level 3).

\section{Measures}

If not stated otherwise, we used scales developed and provided by the authors of the ICCS. For more details on measurement in ICCS see Schulz et al. (2011). A detailed list of all items can be found in the Online Supplement. 


\section{European identity}

Identification with Europe was measured with the same six items used by Keating (2016; e.g., "I see myself as European") on a scale from 1 "strongly disagree" to 4 "strongly agree" (country-level Cronbach alphas ranged from .77 to $.85 ; M=3.06, S D=0.54$ ).

\section{National identity}

Identification with the nation was measured with three items (e.g., "I am proud to live in $<$ country of test $>$ ") on a scale from 1 "strongly disagree" to 4 "strongly agree" (country-level Cronbach alphas ranged from .69 to $.88 ; M=3.24, S D=0.64)$. In order to only measure national belonging, we did not include items that referred to the functioning of the country's political system, its treatment of the environment, whether it is a better place to live than most other countries or whether one should be proud of the country's achievements. In England, the measure of national identity referred to English identity, with one exception. The item referring to the < flag of country of test > referred to the Union Jack (Nelson, Wade, and Kerr 2010).

\section{Migration background}

A categorization of participants based on the country of birth is available in the ICCS dataset. This variable differentiates between native citizens, immigrants (not born in country of assessment), and second-generation citizens (born in country of assessment but who have at least one parent born outside the country). Consistent with previous research (Keating 2016; Verhaegen, Hooghe, and Meeusen 2013) we included these groups as dummy-coded variables with natives as the reference category.

\section{Socioeconomic background}

The ICCS provided the index of socioeconomic background (NISB) derived from parental 
highest occupational level, parental highest educational level, and the approximate number of books at home (the score was standardized to have national means of 0 and SDs of 1).

\section{Political interest}

Using five items, participants indicated their interest (a four-point scale from "not interested at all" to "very interested") in local, national, foreign and international political issues and national social issues (alphas from .82 to $.92 ; M=48.58, S D=10.17$ ).

\section{Opportunities for learning about Europe at school}

Using nine items, students indicated (a four-point response scale from "strongly disagree" to "strongly agree") how much opportunity their school gives them for activities such as finding out what is happening in other European countries or meeting young people from other European countries (alphas from .78 to .85; $M=50.11, S D=9.78$ ).

\section{Trust in EU institutions}

Participants indicated how much they trusted in the European Commission and the European parliament (a four-point response scale from "not at all" to "completely"). We used the mean of these two responses (country-level correlations ranged from .72 to $.89 ; M=2.62, S D=0.80$ ).

\section{Contact activities}

Eight items capture students' participation in activities or groups at the European level. The measure taps into contact with other European cultures or people from other European countries through school trips, holidays, exchange programs, and/or art, music or sports events at home or abroad (country-level Cronbach alphas ranged from .63 to $.83 ; M=50.04$, $S D=9.98)$ 


\section{Discussions about international issues}

Ten items measured students' participation in communication about Europe, capturing students' frequency of engagement with European news and in discussion with parents and peers about various European topics (social, cultural, and political; country-level Cronbach alphas ranged from .81 to $.87, M=50.00, S D=10.02$ ).

\section{Knowledge about the EU}

Four items measured students' self-reported knowledge about the European Union, relating to facts, laws and policies, institutions, and the euro (country-level Cronbach alphas ranged from .70 to $.84, M=50.31, S D=9.91)$.

\section{Proficiency in another European language}

Two items captured students' proficiency in another European language. The first item asked students whether they speak another European language while the second item asks how proficient they are in this language. These two items were combined to measure students' proficiency in another European language on a four-point scale (0 'not', 1 'not very well', 2 'well', and 3 'very well').

\section{Classroom-level variables}

We aggregated student level scores for national identity, socio-economic background, opportunities for learning about Europe, and trust in EU institutions at the classroom level in order to compute classroom average scores for these variables.

\section{Country-level variables}

All derived country-level indices were taken from the year of the ICCS data collection (2009). Country's wealth was represented by its gross domestic product per capita (GDP) 
standardized according to the European Union average (Eurostat 2009a; $M=101.27$,

$\mathrm{SD}=41.56$ ). Income inequality was indicated by the GINI index (Eurostat 2009b; $\mathrm{M}=0.29$,

$\mathrm{SD}=0.04$ ) and gender inequality by the Gender Inequality Index (GII; UNDP 2016; M=0.14,

$\mathrm{SD}=0.06$ ). Immigration friendliness (reflecting how friendly a country's immigration policies

are) was captured by the MIPEX index (Huddleston et al. 2015; $\mathrm{M}=50.52, \mathrm{SD}=12.53$ ).

Communist ( $=1$; eight countries) or non-communist past $(=0 ; 14$ countries) was indicated by a dichotomous variable. Euroscepticism was indexed by country level average scores of trust in EU institutions $(M=2.62, S D=0.14)$. In addition, we aggregated national identity at the country level to compute country-level average scores of national identity and trust in EU.

\section{Data analysis}

We analyzed the data using multilevel linear regression models in Mplus 7.4 (Muthén and Muthén 1998-2015). We used sampling weights at levels 1 and 2 to account for the different selection probabilities at the school level and at the within-school sampling level (for details see Brese et al. 2011). To test our hypotheses, we estimated a series of nested three-level models predicting European and national identity using the maximum likelihood estimator with robust standard errors (MLR) with students at level 1, classrooms at level 2, and countries at level 3. First, we estimated an intercept-only model without predictors to decompose individual-level, classroom-level, and country-level variance (M0).

Second, we added three individual sociodemographic status predictors (gender, immigration and socioeconomic background; M1), and, after that, we added the remaining seven individual predictors (political interest, perceived opportunities for learning about Europe at school, trust in EU institutions, contact activities, discussions about international issues, knowledge about the EU, and language proficiency; M2). All non-dichotomous individual-level predictors were grand mean centred. Third, four classroom-level predictors were added: classroom average socioeconomic background, percentage of students with 
immigrant backgrounds, classroom average perceptions of opportunities for learning about Europe, classroom average trust in EU institutions (M3). Fourth, five country-level predictors were considered: gross domestic product per capita, income inequality, gender inequality, communist past, and national identity. Because of the small sample size at level $3(n=22)$, country-level predictors were tested individually in separate models (M4a-e). Finally, national identity at all three levels was included as predictor to the model predicting European identity (M5a-g).

To test our hypotheses about contextual influences on the relationship between national and European identity, we tested cross-level interactions. First, we estimated randomslope models for national identity at the student and classroom level to test whether its effects significantly varied at higher levels (this model included all level 1 and level 2 predictors and the most important level 3 predictor). If the variance was significant, we tested whether it could be explained by higher-level predictors (i.e. cross-level interactions). For the sake of easier interpretation of significant interactions, simple slopes were computed for higher-level units with lower $\left(25^{\text {th }}\right.$ percentile $)$, median $\left(50^{\text {th }}\right.$ percentile $)$, and higher $\left(75^{\text {th }}\right.$ percentile $)$ levels of the moderator (Aiken and West 1991).

\section{Results}

\section{Preliminary analyses}

Intercept-only models showed that the variance in outcome variables was mainly attributable to differences between individuals (see Notes in Tables 1 and 2). Differences between classrooms accounted for $9 \%$ of the variance in national identity and $6 \%$ of the variance in European identity. Differences between countries accounted for $7 \%$ of the variance in national identity and $6 \%$ of the variance in European identity. There was a moderate overall correlation between national and European identity $(r=.37$; see Figure 1 for a breakdown per country); see Table S1 of the Online supplement for the full correlation table and country- 
level descriptives.

\section{Predictive model of national identity}

On the individual level, national identity was negatively related with being female, having an immigrant background and with higher socioeconomic status (see model M1, Table 1).

However, the contribution of these variables was relatively weak with the exception of the effect for immigrant background $(\beta=-.17, p<.001)$. After adding the other individual-level predictors (Model M2, Table 1), almost all of them were significantly associated with national identity, except for discussions about international issues. Nevertheless, the contribution of these predictors was negligible, except for the effects of opportunities for learning about Europe $(\beta=.11, p<.001)$ and trust in EU institutions $(\beta=.18, p<.001)$. On the classroom level (M3, Table 1), students in classrooms with higher average socioeconomic background $(\beta=-.29, p<.001)$, and higher proportions of students with immigrant background $(\beta=-.35$, $p<.001)$ expressed a lower national identity. Conversely, students in classroom with higher average levels of trust in EU institutions $(\beta=.17, p<.01)$ had a higher national identity. Finally, on the country level (M4a-f), national identity was lower in countries with higher immigration friendliness $(\beta=-.46, p<.05)$.

\section{Predictive model of European identity}

On the individual level, European identity was negatively associated for girls and for students with migration background while it was positively associated with socioeconomic background (see model M1 in Table 2). A look at the standardized coefficients suggests, however, that the contributions of these sociodemographic variables is relatively weak.

After adding the other individual-level predictors (see model M2 in Table 2), almost all of them were significantly associated with European identity, except for political interest. However, examination of the standardized coefficients suggests that the contribution of these 
predictors is negligible except for opportunities for learning about Europe, trust in EU institutions, and knowledge about the EU. On the classroom level (model M3, Table 2), socioeconomic background, percentage of immigrant background students and opportunities for learning about Europe are negatively associated with European identity, while trust in EU institutions is positively associated with European identity. It is important to note that the unstandardized coefficients of the classroom level predictor variables represent contextual or compositional effects because we grand-mean centered our predictor variables (Raudenbush and Bryk 2002; p. 139). This means that when controlling for individual level socioeconomic background and trust in EU institutions average levels of socioeconomic background and trust in EU institutions at the classroom level have independent contextual effects. The same is not true for percentage of immigrant background students and opportunities for learning about Europe at the classroom level because the unstandardized effects are close to zero. At the country-level (models M4a-e, Table 2), European identity was only significantly positively associated with a country's wealth (as reflected by GDP).

In the final models (models M5a-g) we included national identity at the student, classroom and country level. At the individual level, the association between national identity and European identity is significantly positive $(\beta=.27, p<.001)$. Including national identity at the individual level cuts the effect of immigrant background in half, which is no longer significant. National identity is also positively associated with European identity at the classroom level $(\beta=.19, p<.01)$. Because we grand-mean centered our predictor variables the significant estimate of .06 for national identity at the classroom level reflects the difference between the effect of national identity at the student and at the classroom level. It means that when controlling for student-level national identity, an increase of one unit in average national identity at the classroom level, increases European identity by .06 scale units. This indicates that European identity is not only associated with individual student levels of national identity but also with the average levels of national identity in the classroom 
context. Again, including national identity at the classroom level renders the effect of percentage of students with immigrant background non-significant. At the country level, national identity is not significantly associated with European identity.

\section{Moderator analyses}

To understand whether the variance of slopes across contexts is different from zero we tested a random slope model where the slope of national identity was allowed to vary across classrooms and countries. The random-slope model showed that the effect of individual level national identity varied significantly across classrooms $\left(\sigma^{2}=0.014, p<.001\right)$ and countries $\left(\sigma^{2}=0.002, p<.001\right)$. Thus, it was justified to examine whether contextual variables could explain variance in slopes across contexts by testing cross-level interaction effects.

Although it is generally recommended to include all cross-level interaction effects as part of the same model it is also acknowledged that this can lead to issues of insufficient power to detect cross-level interactions and non-convergence in more complex models (Aguinis, Gottfredson, and Culpepper 2013). In our case it was not possible to include all cross-level interaction effects within the same model because such combined models did not converge and therefore we tested the effects of country-level variables separately.

Individual level national identity did not interact significantly with classroom-level SES or country-level GDP. Individual level national identity interacted significantly with classroom-level trust in EU institutions $(B=.03, p=.021)$, with country-level income inequality $(B=-0.40, p=.037)$, gender inequality $(B=-0.56, p<.001)$, immigration friendliness $(B=0.002, p<.001)$, communist past $(B=-0.04, p=.017)$, and country-level trust in EU institutions $(B=.14, p=.026)$. More specifically, the positive effect of individual level national identity was stronger in classrooms with medium to higher average trust in EU institutions $\left(B_{25}=0.21, p<.001 ; B_{50}=0.22, p<.001 ; B_{75}=.22, p<.001\right)$, and in countries with lower as compared to higher income inequality $\left(B_{25}=0.23, p<.001 ; B_{50}=0.22, p<.001\right.$; 
$\left.B_{75}=.21, p<.001\right)$, and gender inequality $\left(B_{25}=0.24, p<.001 ; B_{50}=0.22, p<.001 ; B_{75}=.19\right.$, $p<.001)$. Moreover, the positive relationship between national and European identity was stronger in countries with higher immigration friendliness $\left(B_{25}=0.19, p<.001 ; B_{50}=0.21\right.$, $p<.001 ; B 75=.23, p<.001)$, in countries without a communist past $\left(B_{\text {non-communist }}=0.23, p<\right.$ $\left..001, B_{\text {communist past }}=0.19, p<.001\right)$, and in countries with higher average trust in EU institutions $\left(B_{25}=0.20, p<.001 ; B_{50}=0.22, p<.001 ; B 75=.23, p<.001\right)$.

\section{Additional analyses}

As noted above, including national identity at the individual and classroom level reduced the impact of immigrant background on both the individual and classroom level European identity. Therefore, we conducted an additional analysis testing whether national identity mediated the influence of immigrant background on European identity. Following recommendations on testing mediation in multi-level contexts (Preacher, Zhang, and Zyphur 2011) we set up a multi-level structural equation model with latent variables with immigrant background as the independent variable, national identity as the mediator, and European identity as the dependent variable. The model uses two levels (students within classrooms) and allows to differentiate between indirect effects at the individual and at the classroom level. We first tested this model jointly across all countries before examining the model separately for each country.

The overall model, $\chi 2(24)=638.13, \mathrm{p}<.001, \mathrm{RMSEA}=.019, \mathrm{CFI}=.983, \mathrm{TLI}=$ .970, SRMR within $=.019$, SRMR between $=.078$, showed that the indirect effect from immigrant background to European identity via national identity was significant at both the within level, $I E_{\text {within }}=-.10, S E=.01,95 \% \mathrm{CI}[-.11,-.08]$, and the between level, $I E_{\text {between }}=-$ $.31, S E=.04,95 \% \mathrm{CI}[-.39,-.22]^{4}$. These results indicate that the negative relationship between immigrant background and European identity can in part be explained by the negative relationship between immigrant background and national identity. In other words, 
students with immigrant background are less likely to identify with Europe because they also identify less with their nation of residence. This mediation occurs both at the individual and the classroom level. This means that at the classroom level a higher percentage of students with immigrant background lowers European identity partly because a higher percentage of students with immigrant background also lowers average levels of national identity and this applies to all students, not just those with immigrant background.

Table 3 displays the results, separately for each country. It is evident that at the individual level ( $I E$ within) the negative indirect effect of immigrant background on European identity mediated by national identity is significantly negative in 17 out of 22 countries except for Latvia, Lithuania, Poland, Slovakia, and England. However, the indirect effect at the classroom level ( $\left.I E_{\text {between }}\right)$ is only significantly negative in six out of 22 countries. Moreover, in 5 countries this effect could not be reliably estimated. Thus, the indirect effect at the individual level can be generalized to most European countries while the indirect effect at the classroom level seems to be driven by a few select countries and is less reliable (as indicated by relatively large standard errors and our inability to estimate the effect in some countries).

\section{Discussion}

This study found that the association between adolescents' national and European identity is moderately positive and stable across countries. Yet, social context moderates the relationship between national and European identity among adolescents in Europe. While national identity was generally positively associated with European identity in all examined countries, the size of this association varied as a function of factors at the classroom and country level. The relationship between national and European identity was weaker for adolescents attending classrooms or living in countries with lower average levels of trust in EU institutions. Likewise, living in countries with higher gender and income inequalities, less friendly immigration policies, and a communist past lessened the association between national and 
European identity.

The high stability of correlations between adolescents' national and European identity across countries (see Figure 1) was surprising considering previous findings. Studies with adults have found much greater variation in the relationship between these two identities across European countries (Duchesne and Frognier 2008), with very low correlations in countries like the United Kingdom. One would expect that in countries where societal discourse about the EU has been very negative and has ultimately led to it seeking to leave the EU, the relationship should be lower. However, this is not what we observed among adolescents, which may suggest that adolescents may have not picked up on these different societal trends that affect adults. On the other hand, qualitative data suggest that in countries like Germany which promote European agendas and implement those in national school curricula, young people are more likely to see a European identity as compatible with their national identity than in countries like Great Britain where discourse about the EU is overwhelmingly negative (Faas 2007b). One possible reason why these differences were not detected in our study is that school curricula primarily impact students' intellectual representations of identity, which emerge in qualitative interviews, but not general identityrelated feelings captured in our study.

Our central assumption derived from SCT was that contextual factors that may make national and European identity more or less compatible should moderate their relationship. Our moderator analyses confirmed these assumptions in the case of trust in EU institutions, income and gender inequality, immigration friendliness, and communist past but not for collectively shared economic hardship (i.e., classroom-level SES or country-level GDP). In line with our assumptions it seemed that the social norms of distrust in the EU, present in one's environment, undermined the individual-level compatibility between national and European identity. Similarly, both identities were less compatible among adolescents from post-communist countries and countries with harsher immigration policies, which could be 
explained by their more ethno-culturally based or exclusive national identities. From this perspective, it should be taken into account that the relationship between national and European identity depends on the specific content of national identity. While support for European integration is positively related to general attachment to the nation, it is strongly negatively related to exclusive forms of national identity, that is (i.e., seeing oneself only as a member of the nation; Hooghe and Marks 2004)). Similarly varying effects of different contents of national identity have also been documented for anti-immigration and antiminority attitudes (e.g., Pehrson, Vignoles, and Brown 2009). Future research should differentiate between different dimensions of national identity, which was not possible within this dataset. That income and gender inequality but not collectively shared economic hardship act as moderators suggests that relative deprivation is more important than absolute deprivation, which has also been shown for other outcomes, such as health (e.g., Wilkinson 1997), and is a central tenet of relative deprivation theory (Walker and Smith 2002).

However, it should be noted that while we were able to establish contextual factors that moderated the extent to which national identity was related to European identity, these variations were moderations in degree, rather than in kind. Thus, it was never the case that these contextual factors made national and European identity completely incompatible, such that national identity would be negatively related to European identity in specific contexts (e.g., in countries with lower trust in EU institutions).

The predictive models for national and European identity showed few differences between predictor variables across both outcomes. Together with the consistent moderate correlations between national and European identity the similarity in predictors suggests that national and European identity share a common basis. However, other research found that national identity is positively and European identity negatively related to ethno-centrism (Boehnke \& Fuss, 2008), suggesting that both identities also have unique and unshared origins. In addition, Agirdag and colleagues (2016) showed that ethnic variables (such as host 
language use, interethnic friendships and religiosity) are more strongly associated with national than with European identity. Thus, future research should continue to discern the shared and unshared sources of variance between national and European identity.

In addition, we found a negative impact of immigrant background on European identity that was mediated by national identity. That is, adolescents with immigrant backgrounds were less likely to identify with Europe because they were less likely to identify with their nation of residence, a mediation effect occurring mainly at the individual level. Previous studies have already shown that adolescents with immigrant backgrounds are less likely to identify with Europe than ethnic majority adolescents (Verhaegen, Hooghe, and Meeusen 2013; Keating 2016; Agirdag, Huyst, and van Houtte 2012; Agirdag, Phalet, and van Houtte 2016). Our results suggest one reason for this persistent finding may be the generally lower levels of national identity among adolescents with immigrant backgrounds (Verkuyten and Martinovic 2012). Scholars have argued that adolescents with immigrant backgrounds face structural impediments to developing a national identity because national identity is still much more ethnically (i.e., referring to the ethnic majority group) than civically defined in most European countries (Agirdag, Phalet, and van Houtte 2016; Alba 2005). In contrast, European identity has been promoted as a viable unifying alternative for adolescents with immigrant backgrounds because of its civic foundation (Agirdag, Phalet, and van Houtte 2016; Erisen 2016). Our results are sobering in this respect because they suggest that national identity is one of the most important predictors of European identity and that therefore adolescents with immigrant backgrounds are at a major disadvantage compared to ethnic majority adolescents.

Moreover there was also some evidence that the percentage of adolescents with immigrant backgrounds in a classroom affected European identity negatively and that this was due to their negative impact on average levels of national identity in the classroom. However, this finding has to be treated with caution because separate analyses for each country 
suggested that this effect was particular to a few (six) individual countries and that the effect was less reliable. Nevertheless, this finding may suggest that it is problematic to have classrooms, where the majority of students have an immigrant background because of the negative impact this may have for the European identity of students in these classrooms. Ample research shows that very high concentrations of students with immigrant backgrounds in a classroom are problematic also for other reasons because they are associated with lower academic achievement, particularly among ethnic minority groups (Thijs and Verkuyten 2014; Teltemann and Schunck 2016; van Ewijk and Sleegers 2010). Thus, despite wellknown positive effects of classroom ethnic diversity on students' support for immigrants' rights, tolerance, and multiculturalism (Isac, Maslowski, and van der Werf 2012; Janmaat 2012; van Geel and Vedder 2011), its negative impacts should be considered as well.

\section{Limitations}

This study also has a number of limitations. First, our analyses is based on cross-sectional data, which makes causal interpretations problematic. The causality between European and national identity can be bidirectional as well as the causality between identity and institutional trust and other predictors. Second, in analysing data across European countries we do not differentiate between different regions within those countries. However, there is research suggesting that levels of national and European identity may differ between regions within a country, such that national and European identification are lower in the Basque Country of Spain than in Madrid (Boehnke and Fuss 2008). However, different levels of identification do not necessarily imply different relationships between national and European identification and another study from Spain does not find differences in the relationship between national and European identity across different regions in Spain (Medrano and Gutiérrez 2001). Moreover, both national and European identity were measured using similarly structured, positively phrased questionnaire items. Thus, the resulting correlation between national and 
European identity might be overestimated due to shared-method variance, and it is likely that somewhat lower correlations would have been be obtained if more dissimilar methods had been used. Finally, we were not able to differentiate between different forms of national identity (e.g., patriotic vs. nationalistic) with this given dataset. Other studies have found that only positive attachment (i.e. patriotism) but not exclusive forms of national identity (i.e. nationalism) are related to support for European integration (Hooghe and Marks 2004).

\section{Conclusion}

Overall, our results point to the powerful effects of context in shaping the relationship between national and European identity. The two most important context factors were how much other adolescents in their classroom or their country trust the EU and various indicators of relative deprivation at the country level. Results suggested that the overall positive relationship between national and European identity is weaker if the context is distrustful of the EU or is characterized by greater social and economic inequalities. 


\section{References}

Agirdag, Orhan, Petra Huyst, and Mieke van Houtte. 2012. "Determinants of the Formation of a European Identity among Children: Individual- and School-Level Influences." JCMS: Journal of Common Market Studies 50 (2): 198-213. doi:10.1111/j.14685965.2011.02205.x.

Agirdag, Orhan, Karen Phalet, and Mieke van Houtte. 2016. "European identity as a unifying category: National vs. European identification among native and immigrant pupils.” European Union Politics 17 (2): 285-302. doi:10.1177/1465116515612216.

Aguinis, Herman, Ryan K. Gottfredson, and Steven A. Culpepper. 2013. "Best-Practice Recommendations for Estimating Cross-Level Interaction Effects Using Multilevel Modeling.” Journal of Management 39 (6): 1490-1528. doi:10.1177/0149206313478188.

Aiken, L. S., and S. G. West. 1991. Multiple regression: Testing and interpreting interactions. Newbury Park: Sage.

Alba, Richard. 2005. "Bright vs. blurred boundaries: Second-generation assimilation and exclusion in France, Germany, and the United States." Ethnic and Racial Studies 28 (1): 20-49. doi:10.1080/0141987042000280003.

ANDERSON, CHRISTOPHER J. 1998. "When in Doubt, Use Proxies: Attitudes toward domestic politics and support for European integration." Comparative Political Studies 31 (5): 569-601. doi:10.1177/0010414098031005002.

Barrett, Martyn. 2007. Children's Knowledge, Beliefs and Feelings about Nations and National Groups. Hove: Psychology Press.

Barrett, Martyn. 2015. “An integrative model of political and civic participation: Linking the An integrative model of political and civic participation: Linking the macro, social, and psychological levels of explanation." In Political and civic engagement: Multidisciplinary perspectives, edited by Martyn Barrett and Bruna Zani, 162-87. Hove: Routledge. 
Boehnke, Klaus, and Daniel Fuss. 2008. "What Part Does Europe Play in the Identity Building of Young European Adults?" Perspectives on European Politics and Society 9 (4): 466-79. doi:10.1080/15705850802416887.

Brese, F., M. Jung, P. Mirazchiyski, W. Schulz, and O. Zuehlke. 2011. ICCS 2009 User Guide for the International Database. Amsterdam: IEA.

Brinegar, A. P., S. K. Jolly, and H. Kitschelt. 2004. "Varieties of capitalism and political divides over European integration.” In European Integration and Political Conflict, edited by Gary Marks and M. R. Steenbergen, 62-89. Cambridge: Cambridge University Press.

Bronfenbrenner, U. 1979. The ecology of human development. Experiments by nature and design. Cambridge, MA: Harvard University Press.

Bruter, M. 2005. Citizens of Europe? The emergence of a mass European identity. Basingstoke: Palgrave Macmillan.

Duchesne, Sophie, and André-Paul Frognier. 2008. "National and European Identifications: A Dual Relationship.” Comparative European Politics 6 (2): 143-68. doi:10.1057/palgrave.cep.6110128.

Eichenberg, Richard C., and Russell J. Dalton. 1993. "Europeans and the European Community: The dynamics of public support for European integration.” International Organization 47 (04): 507. doi:10.1017/S0020818300028083.

Erisen, Elif. 2016. "Seeking refuge in a superordinate group: Non-EU immigration heritage and European identification.” European Union Politics 18 (1): 26-50. doi:10.1177/1465116516680301.

Eurostat. 2009a. "GDP per capita in PPS." http://ec.europa.eu/eurostat/tgm/table.do?tab=table\&init=1\&language=en\&pcode=tec00114 \&plugin $=1$.

Eurostat. 2009b. "Gini coefficient of equivalised disposable income: EU-SILC survey." http://appsso.eurostat.ec.europa.eu/nui/show.do?dataset=ilc_di12\&lang=en. 
Faas, Daniel. 2007a. "The Europeanisation of German ethnic identities: The case of German and Turkish students in two Stuttgart secondary schools." International Studies in Sociology of Education 17 (1/2 // 1-2): 45-62. doi:10.1080/09620210701433738.

Faas, Daniel. 2007b. "Youth, Europe and the Nation: The Political Knowledge, Interests and Identities of the New Generation of European Youth." Journal of Youth Studies 10 (2): 161-81. doi:10.1080/13676260601120161.

Fuss, Daniel. 2006. "Exclusive vs. inclusive? Attitudes toward Foreigners in the context of national and European identity." Zeitschrift für Soziologie der Erziehung und Sozialisation 26 (1): 69-85. Accessed September 19, 2017.

Habermas, J. 2011. Zur Verfassung Europas. Ein Essay. [On Europe's constitution. An essay]. Frankfurt a. M. Suhrkamp.

Hadler, Markus, Kiyoteru Tsutsui, and Lynn G. Chin. 2012. "Conflicting and reinforcing identities in expanding Europe: Individual- and country-level factors shaping national and European identities, 1995-2003.” Sociological Forum 27 (2): 392-418. doi:10.1111/j.15737861.2012.01323.x.

Hooghe, Liesbet, and Gary Marks. 2004. "Does identity or economic rationality drive public opinion on European integration?" Political Science and Politics 37 (3): 415-20. http://www.jstor.org/stable/4488854. Accessed September 22, 2017.

Hooghe, Marc, and Soetkin Verhaegen. 2017. "The effect of political trust and trust in European citizens on European identity.” European Political Science Review 9 (02): 16181. doi:10.1017/S1755773915000314.

Hornsey, Matthew J. 2008. "Social Identity Theory and Self-categorization Theory: A Historical Review.” Social and Personality Psychology Compass 2 (1): 204-22. doi:10.1111/j.1751-9004.2007.00066.x.

Huddleston, T., O. Bilgili, A.-L. Joki, and et al. 2015. "Migrant Integration Policy Index 2015." www.mipex.eu. 
Isac, Maria M., Ralf Maslowski, and Greetje van der Werf. 2012. "Native Students Attitudes towards Equal Rights for Immigrants. A Study in 18 European Countries.” 270 kB / JSSE Journal of Social Science Education, 1-2012: Comparative Studies of Civic and Citizenship Education. doi:10.4119/UNIBI/jsse-v11-i1-1189.

Janmaat, Jan G. 2012. "The Effect of Classroom Diversity on Tolerance and Participation in England, Sweden and Germany." Journal of Ethnic and Migration Studies 38 (1): 21-39. doi:10.1080/1369183X.2012.640007.

Keating, Avril. 2016. “Are cosmopolitan dispositions learned at home, at school, or through contact with others? Evidence from young people in Europe.” Journal of Youth Studies 19 (3): 338-57. doi:10.1080/13676261.2015.1072617.

Medrano, Juan D., and Paula Gutiérrez. 2001. "Nested identities: National and European identity in Spain.” Ethnic and Racial Studies 24 (5): 753-78. doi:10.1080/01419870120063963.

Muthén, L. K., and B. O. Muthén. 1998-2015. Mplus User's Guide: Seventh Edition. Los Angeles, CA: Muthén \& Muthén.

Nelson, Julie, Pauline Wade, and David Kerr. 2010. Young people's civic attitudes and practices: England's outcomes from the IEA International Civic and Citizenship Education Study (ICCS). London: Department of Education. Accessed April 26, 2018. https://assets.publishing.service.gov.uk/government/uploads/system/uploads/attachment_da ta/file/181802/DFE-RR060.pdf.

Norris, P., and R. Inglehart. 2009. Cosmopolitan Communications: Cultural Diversity in a Globalized World. New York: Cambridge University Press.

Paskov, Marii, and Caroline Dewilde. 2012. "Income inequality and solidarity in Europe." Research in Social Stratification and Mobility 30 (4): 415-32. doi:10.1016/j.rssm.2012.06.002. 
Pehrson, Samuel, Vivian L. Vignoles, and Rupert Brown. 2009. "National Identification And Anti-Immigrant Prejudice: Individual And Contextual Effects Of National Definitions.” Social Psychology Quarterly 72 (1): 24-38. doi:10.1177/019027250907200104.

Preacher, Kristopher J., Zhen Zhang, and Michael J. Zyphur. 2011. “Alternative methods for assessing mediation in multilevel data: The advantages of multilevel SEM.” Structural Equation Modeling: A Multidisciplinary Journal 18 (2): 161-82. doi:10.1080/10705511.2011.557329.

Raudenbush, Stephen W., and Anthony S. Bryk. 2002. Hierarchical linear models: Applications and data analysis methods. 2nd Ed. Thousand Oaks, CA: Sage. Rutland, Adam, and Marco Cinnirella. 2000. "Context effects on Scottish national and European self-categorization: The importance of category accessibility, fragility and relations.” British Journal of Social Psychology 39 (4): 495-519. doi:10.1348/014466600164606.

Savvides, Nicola, and Daniel Faas. 2016. "Does Europe Matter? A Comparative Study of Young People's Identifications with Europe at a State School and a European School in England.” European Journal of Education 51 (3): 374-90. doi:10.1111/ejed.12127.

Schulz, W., J. Ainley, and J. Fraillon. 2011. ICCS 2009 Technical Report. Amsterdam: IEA. Šerek, Jan, and Philipp Jugert. 2017. "Young European citizens: An individual by context perspective on adolescent European citizenship.” European Journal of Developmental Psychology. doi:10.1080/17405629.2017.1366308.

Smith, Anthony D. 1992. "National identity and the idea of European unity." International Affairs 68 (1): 55-76. doi:10.2307/2620461.

Tajfel, Henri, and John C. Turner. 1979. "The social idenitity theory of intergroup behavior." In The Psychology of intergroup relations, edited by S. Worchel and W. G. Austin, 33-47. Monterey, CA: Brooks/Cole. 
Teltemann, Janna, and Reinhard Schunck. 2016. "Education systems, school segregation, and second-generation immigrants' educational success: Evidence from a country-fixed effects approach using three waves of PISA.” International Journal of Comparative Sociology 57 (6): 401-24. doi:10.1177/0020715216687348.

Thijs, Jochem, and Maykel Verkuyten. 2014. "School ethnic diversity and students' interethnic relations." British Journal of Educational Psychology 84: 1-21.

Turner, John C., Michael A. Hogg, Penelope J. Oakes, Stephen D. Reicher, and Margaret S. Wetherell. 1987. Rediscovering the social group: A self-categorization theory. Rediscovering the social group: A self-categorization theory. Cambridge: Basil Blackwell. UNDP. 2016. "Human development report 2016: Human development for everyone." http://hdr.undp.org/sites/default/files/2016_human_development_report.pdf.

van Ewijk, Reyn, and Peter Sleegers. 2010. "Peer ethnicity and achievement: A meta-analysis into the compositional effect." School Effectiveness and School Improvement 21 (3): 23765. doi:10.1080/09243451003612671.

van Geel, Mitch, and Paul Vedder. 2011. "Multicultural attitudes among adolescents." Group Processes \& Intergroup Relations 14 (4): 549-58. doi:10.1177/1368430210379007.

Verhaegen, Soetkin, and Marc Hooghe. 2015. "Does more knowledge about the European Union lead to a stronger European identity? A comparative analysis among adolescents in 21 European member states.” Innovation: The European Journal of Social Science Research 28 (2): 127-46. doi:10.1080/13511610.2014.1000836.

Verhaegen, Soetkin, Marc Hooghe, and Cecil Meeusen. 2013. “Opportunities to learn about Europe at school. A comparative analysis among European adolescents in 21 European member states." Journal of Curriculum Studies 45 (6): 838-64. doi:10.1080/00220272.2013.800995. 
Verhaegen, Soetkin, Marc Hooghe, and Ellen Quintelier. 2014. "European Identity and Support for European Integration: A Matter of Perceived Economic Benefits?” Kyklos 67 (2): 295-314. doi:10.1111/kykl.12055.

Verkuyten, Maykel, and Borja Martinovic. 2012. “Immigrants' National Identification: Meanings, Determinants, and Consequences.” Social Issues and Policy Review 6 (1): 82112. doi:10.1111/j.1751-2409.2011.01036.x.

Walker, Ian, and H. J. Smith. 2002. "Fifty years of relative deprivation research.” In Relative deprivation: Specification, development, and integration, edited by Ian Walker and H. J. Smith, 1-12. Cambridge: Cambridge University Press.

Wilkinson, R. G. 1997. "Socioeconomic determinants of health. Health inequalities: relative or absolute material standards?” British Medical Journal 314 (7080): 591-95.

Wilkinson, Richard G., and Kate E. Pickett. 2017. “The enemy between us: The psychological and social costs of inequality.” European Journal of Social Psychology 47 (1): 11-24. doi:10.1002/ejsp.2275. 